\title{
Endovascular surgery: Has it improved outcomes?
}

Anton Surath Dias Perera, MBBS ${ }^{1}$ Diplomate of American Board of Surgery (General Surgery)

Diplomate of American Board of Surgery (Vascular Surgery)

1 Vascular Surgeon/Clinical Assistant Professor of Surgery, University of Tennessee, Memphis and Cardiovascular Surgery Clinic PLLC, Memphis, Tennessee, USA.

Key words: Aneurysms; Endovascular repair; Stents.

\section{Introduction}

The field of endovascular surgery is a relatively new addition to the vascular surgery armamentarium. It has its origins in the realm of interventional radiology and interventional cardiology. However it was the pioneering work of Parodi [1] and Palmaz [2], who used these techniques to repair aortic pathology such as aortic aneurysms and arterial stenoses, which alerted vascular surgeons to take note of the tremendous potential of endovascular approach. Since then, vascular surgeons have quickly adopted this new technology, and soon endovascular surgery became integrated into surgical training programs. As a result, the modern vascular surgeon is equally adept at both endovascular and open technique. Technical basis of all endovascular procedures is obtaining wire access into the target vessel. This is done either percutaneously or via open method depending on the intended procedure. Using the wire as the platform, different type of devices can be used to treat vascular pathology. They include balloon catheters for angioplasty, stent systems to treat stenoses, plaque excision devices for atherectomy, and stent-graft systems to repair aneurysms. The advantages of percutaneous endovascular procedures include the avoidance of general anesthesia and

Correspondnce: A.S.N. Dias Perera, Vascular Surgeon / Clinical

Assistant Professor of Surgery, University of Tennessee, Memphisand

Cardiovascular Surgery Clinic PLLC, Memphis, Tennessee, USA.

Email: surathdp@yahoo.com

The Sri Lanka Journal of Surgery 2010; 28(2):6-12. incision-related wound complications, reduced cardiovascular stress, and earlier recovery and ambulation. When required, re-intervention can also be performed more easily.

Ostial lesions, complex stenoses, occlusions, and aneurysms can be treated using existing technology with excellent outcomes. Occlusive disease of aorto-iliac, femoral-popliteal, subclavian, carotid, renal and tibial segments can be treated with balloon angioplasty and stents. Aneurysms of the thoracic and abdominal aorta and peripheral arteries can be treated with stent grafts. Newer stent grafts are being developed to treat complex aortic pathology such as thoracoabdominal aneurysms, aortic arch lesions and aortic dissection. Some of these devices are already being used in clinical trials in the United States and Europe [3]. There is a preponderance of high quality data that show excellent outcomes of endovascular surgery in all vascular beds. However, it is useful to examine several specific areas and pathology where endovascular approach has been scientifically evaluated in large multi-center clinical trials, viz. thoracic and abdominal aortic aneurysms, carotid artery stenoses and peripheral vascular disease.

\section{Endovascular repair of abdominal aortic aneurysms}

Since the introduction of first generation endovascular stent grafts, e.g. AneuRx stent graft [4], for repair of abdominal aortic aneurysms (AAA), we have seen rapid 
advances in this field. Devices currently available for use in the United States are all second-generation devices that have seen further improvements since their first introduction (Cook Zenith ${ }^{\circledR}$, Gore Excluder $\AA$, Medtronic Talent/Endurant $\AA$, and Endologix Powerlink $($ )). The efficacy of endovascular (EVAR) versus open repair of AAAs was studied in two European, multi-center, randomized clinical trials (Endovascular Aneurysm Repair Trial 1(EVAR-1) and The Dutch Randomized Endovascular Aneurysm Management Trial(DREAM)) in which patients with large aneurysms ( $>5.5$ for EVAR-1 and $>5.0 \mathrm{~cm}$ for DREAM) were randomized to open repair or EVAR [5,6]. Primary endpoint was overall mortality. In both trials, 30-day mortality was lower with EVAR compared to open repair $(1.7 \%$ versus $4.7 \%$ in EVAR- 1 and $1.2 \%$ versus $4.6 \%$ in DREAM). Four (4) years after randomization, all-cause mortality was similar in the two groups (about 28\%) and the survival rates were similar. However, the rate of re-interventions was higher in the EVAR group. In the United States, the OVER trial (Open versus Endovascular Repair) showed similar results [7]. Following these results, EVAR has been widely adapted as the first-line therapy for
AAAs with suitable anatomy. However, we still do not have longterm data for these patients, i.e. $10-20$ year outcomes. Therefore, for younger patients, with low cardiac and medical risk, open repair should still be offered as a first line treatment option.

\section{Endovascular repair of thoracic aortic aneurysms}

Open repair of thoracic aortic aneurysms have traditionally been associated with high perioperative mortality and morbidity (up to $10 \%$ and $50 \%$ respectively). Introduction of endovascular stent grafts to treat descending thoracic aortic aneurysms (DTAA) once again changed the "playing field." According to the data extracted from non-randomized but prospective databases used for regulatory trials for the United States Food and Drug Administration (FDA) approval, the reduction in mortality and major perioperative comorbidities such as respiratory failure and paraplegia has been considerable [8,9] (Table 1). A recent meta-analysis of endovascular intervention versus open surgery for thoracic aortic pathology revealed similar outcomes: mortality in the stenting group was $5.57 \%$

Table 1. Summary of Results from Three Regulatory Trials and One Large registry from Europe for Endovascular Repair of Descending Thoracic Aortic Aneurysms (DTAA)

FDA Regulatory Trials

\begin{tabular}{lccccc}
\cline { 2 - 5 } & $\begin{array}{c}\text { Gore } \\
\text { TAG } \\
\text { Study }\end{array}$ & STARZ & VALOR & $\begin{array}{c}\text { Combined Open } \\
\text { Repair Controls } \\
\text { from Trials }\end{array}$ & $\begin{array}{c}\text { Eurostar + } \\
\text { UK Registry }\end{array}$ \\
\hline Stent Graft & TAG & TX2 & Talent & - & Multiple \\
Patient No. & 140 & 160 & 195 & 353 & 249 \\
& & $\mathbf{3 0 - d a y}$ Outcomes: & & 5.3 \\
Mortality (\%) & 1.5 & 1.9 & 2.1 & 7.1 & 4 \\
*SCI (\%) & 2.8 & 5.6 & 8.7 & 13 & 2.8 \\
Stroke (\%) & 3.5 & 2.5 & 3.6 & 6.7 & - \\
**MAE (\%) & 28 & 41.9 & 30 & 77.3 & 2.4 \\
Vascular & 14 & 22 & 9.2 & 16.3 & \\
Complications (\%) & & & & & \\
\hline
\end{tabular}


compared to and $16.5 \%$ in the open arm. Similarly, the incidence of major neurological complications was $5.4 \%$ in the stent patients and $14 \%$ in open patients [9]. According to follow up data, these early benefits of thoracic endovascular aneurysm repair (TEVAR) appear to persist up to 5-years. In view of these findings, it is inconceivable that we will ever have a randomized clinical trial to compare endovascular versus open treatment for DTAA. Therefore, TEVAR has become the preferred treatment modality for all patients with DTAA who have suitable anatomy. Endovascular repair has also been used to repair aortic arch aneurysms and thoracoabdominal aortic aneurysms using either hybrid technique (endograft exclusion of the aorta with open bypass of critical aortic branches) or fenestrated stent grafts. Early results, though encouraging, have not shown conclusive benefit over open repair $[10,11,12,13]$. It is likely that in near future we will see some form of a prospective clinical trial to evaluate the outcomes of endovascular versus open treatment of aortic arch pathology and thoracoabdominal aneurysms.

\section{Endovascular treatment of carotid disease}

Several, landmark multi-center randomized clinical trials in Europe and North America have firmly established efficacy of carotid endarterectomy (CEA) for stroke prevention
$[14,15,16,17]$. The open surgical technique has become so refined over the years that routine carotid endarterectomy in the United States has a reported stroke and death rate of only 2 percent [18]. However in both high medical risk patients and in those undergoing re-operative carotid surgery, risk of stroke, myocardial infarction and nerve injury is higher. Carotid angioplasty and stenting (CAS) was attempted in these patients to minimize the above complications. Several large case series and clinical trials reported good outcomes but these were flawed in terms of scientific method to be considered as the highest level of evidence. Therefore, two large, simultaneous trials, Carotid Revascularization Endarterectomy vs. Stenting Trial (CREST) and International Carotid Stenting Study (ICSS), were conducted in the United States and Europe respectively to directly compare CAS with CEA $[19,20]$. The North American CREST trial showed that the two techniques were equivalent when stroke, death and myocardial infarction were considered together as a composite endpoint ( $5.2 \%$ versus $4.5 \%)$. When individual endpoints were analyzed, the stroke rate was twice as high with CAS compared CEA (4.1\% vs. $2.3 \%$ ). CAS patients had lower rate of myocardial infarction. Overall, the quality of life of patients was affected more by stroke (Table 2). In the European ICSS trial, which incidentally had a higher overall stroke and death rate when compared to the CREST trial,

Table 2. CREST Trial Outcome: Primary endpoint, components of primary endpoint and other events according to the treatment group

\begin{tabular}{|c|c|c|c|c|}
\hline \multirow[t]{2}{*}{ End Point } & $\begin{array}{c}\text { CAS } \\
(\mathrm{N}=1252)\end{array}$ & $\begin{array}{c}\text { CEA } \\
(\mathrm{N}=\mathbf{1 2 4 0})\end{array}$ & \multirow{2}{*}{$\begin{array}{c}\text { Hazard Ratio } \\
\text { for CAS vs. } \\
\text { CEA (95\% CI) }\end{array}$} & \multirow[t]{2}{*}{ P Value } \\
\hline & \multicolumn{2}{|c|}{$(\%)$} & & \\
\hline Death & 0.7 & 0.3 & 2.25 & 0.18 \\
\hline Stroke & 4.1 & 2.3 & $1 / 79$ & 0.01 \\
\hline Myocardial Infarction (MI) & 1.1 & 2.3 & 0.50 & 0.03 \\
\hline $\begin{array}{l}\text { Primary end point (Stroke, } \\
\text { MI or death) }\end{array}$ & 5.2 & 4.5 & 1.18 & 0.38 \\
\hline
\end{tabular}




\begin{tabular}{|c|c|c|c|c|c|}
\hline & $\begin{array}{l}\text { Stenting group } \\
\qquad(\mathbf{N}=\mathbf{8 5 3})\end{array}$ & $\begin{array}{l}\text { Endarterectomy } \\
\qquad(\mathbf{n}=\mathbf{8 5 7})\end{array}$ & \multirow{2}{*}{$\begin{array}{l}\text { Hazard } \\
\text { ratio } \\
(95 \% \mathrm{CI})\end{array}$} & \multirow{2}{*}{$\begin{array}{c}\text { Risk } \\
\text { difference, \% } \\
(95 \% \mathrm{CI})\end{array}$} & \multirow[t]{2}{*}{ P Value } \\
\hline & \multicolumn{2}{|c|}{$(\%)$} & & & \\
\hline $\begin{array}{l}\text { Stroke, death or } \\
\text { myocardial infarction }\end{array}$ & 8.5 & 5.2 & 1.69 & $3.3 \%$ & 0.006 \\
\hline Any stroke & 7.7 & 4.1 & 1.92 & $3.5 \%$ & 0.002 \\
\hline Any stroke or death & 8.5 & 4.7 & 1.86 & $3.8 \%$ & 0.001 \\
\hline All-cause death & 2.3 & 0.8 & 2.27 & $1.45 \%$ & 0.017 \\
\hline
\end{tabular}

CEA was superior for all endpoints (Table 3). The verdict from these two large trials did not leave a clear victor. Instead, the current consensus is to consider both CEA and CAS as complimentary procedures for treatment of carotid disease, and the choice of procedureshould be individualized according to patient risk factors and comorbidities. One important caveat is that CEA was found to be safer in patients over age of 80 years. The presumption is that the calcified aorta and tortuous aortic arch anatomy in older patients placed them at higher risk for stroke during CAS.

\section{Endovascular treatment of peripheral vascular disease}

Peripheral arterial occlusive disease involves the aorto-iliac, femoro-popliteal and tibial arterial segments. Open bypass still remains the gold standard to which all other treatment approaches to aorto-iliac occlusive disease (AIOD) is compared. Procedures such as aortofemoral, ilio-femoral and femoro-femoral bypass have proven long-term patency. The primary patency rates of aorto-femoral bypass and femoro-femoral bypass are approximately $90 \%$ and $70 \%$ respectively at 5 years $[21,22,23,24]$. Compared to these results, 5year, secondary patency of TASC (TransAtlantic Inter-Society Consensus Document on Management of Peripheral Arterial Disease) $\mathrm{A}$ and $\mathrm{B}$ lesions following angioplasty and stenting is reported at around 80 percent
$[25,35]$. However, endovascular intervention for TASC C and D lesions (more diffuse disease including chronic total occlusions, bilateral occlusions and disease extending to external iliac arteries) has markedly inferior patency rates of around $75 \%$ at 2 years [26,27]. Therefore, in the aorto-iliac segment, angioplasty and stenting is considered first line therapy for TASC A a nd B lesions whereas open surgery is indicated for most TASC C and D lesions.

In the femoro-popliteal segment, angioplasty and stenting is widely used to treat both claudicants and patients with critical limb ischemia. More recently, other techniques such as excisional atherectomy, cryoplasty and laser atherectomy have also been used. No comprehensive clinical trial has been conducted to assess the efficacy of endovascular intervention versus open bypass across all clinical groups. Instead, limited trial data is available for angioplasty in the femoro-popliteal segment for mixed group of patients with claudication and critical limb ischemia. Open bypass patients had superior patency rate but higher long-term mortality compared to the angioplasty group In the BASIL (The Bypass versus Angioplasty in Severe Ischemia of the Leg) trial [28]. Other reported literature reflects retrospective data from cases series. Overall patency rate of angioplasty and stenting ranges $63 \%$ to $66 \%$ at 2 years in these analyses $[29,30]$. A more recent study reported overall 36-month primary, primary-assisted, and secondary patency rates of $52 \%, 64 \%$, and $59 \%$, 
respectively following primary stenting of superficial femoral artery [31]. This must be compared with femoro-popliteal bypass surgery, which has a reported 4-year patency of up to 80 percent. In spite of the paucity of high quality data, endovascular interventions have been widely adapted as the first line treatment approach to treat femoro-popliteal disease. For the patients, morbidity and mortality associated with open surgery and long hospital stay are avoided. In addition, endovascular intervention has enabled us to revascularize patients who are otherwise considered too-high risk for open surgery. For management of tibial occlusive arterial disease, there are very few durable treatment options. Many different endovascular interventions including atherectomy, angioplasty and laser treatments are performed [32]. None have proven to be durable. For limb salvage, open distal bypass remains the proven treatment. However, in major centers with experienced practitioners and close surveillance programs, encouraging results have been reported with tibial angioplasty. These patients however need many secondary interventions to ensure patency and amputation -free survival.

\section{Endovascular surgery in other vascular beds}

Angioplasty and stenting of renal artery lesions is widely performed by interventionists and vascular surgeons all over the world. In general, renal artery revascularization for salvage of renal function or for treatment of hypertension remains controversial. Recently concluded Angioplasty and Stenting for Renal Artery Lesions (ASTRAL) trial showed no benefit following angioplasty and stenting for asymptomatic renal artery stenoses [33]. A multi-center, randomized trial looking at different endpoints is underway in the United States [34]. In other areas, the use of endovascular technique continues to expand: salvage of dialysis access grafts, treatment upper extremity arterial stenosis, endovenous ablation therapy for superficial venous reflux, and treatment of acute and chronic mesenteric ischemia. However, long-term data is not available to evaluate the efficacy of these approaches compared to standard open surgery.

\section{Summary}

Endovascular surgery is rapidly replacing open surgery as the primary means of providing therapy in many areas of vascular surgery. As a result, the modern vascular surgeon should be able to offer a full spectrum of treatment options ranging from percutaneous interventions to open surgery to his or her patients. At a recent meeting in the United States, a senior vascular surgeon remarked "vascular surgery is the most exciting field to be in practice today". By embracing endovascular surgery, modern vascular surgeons have expanded their scope of practice and treatment strategies by many folds. As an example, complex aortic aneurysms that could not be treated by open surgery are now being treated by combined endovascular and open surgical strategies, i.e. hybrid procedures. Typically, this involves excluding the affected aneurysmal segment with endografts while bypassing the critical aortic branches in that segment (i.e. renal, mesenteric, carotid or subclavian arteries, depending on the segment of the aorta excluded) using bypass grafts with inflow from either distal or proximal aorta. Therefore, the advent of endovascular surgery has not only improved treatment outcomes in many areas of vascular surgery, it has also vastly broadened our scope of treatment of vascular pathology. Future developments in technology, clinical practice and vascular surgical training will only serve to further enhance this very exciting facet of modern surgery.

\section{References}

1. Parodi JC, Palmaz JC, Barone HD. Transfemoral intraluminal graft implantation for abdominal aortic aneurysm. Ann Vasc Surg 1991; 5:491499.

2. Palmaz JC, Sibbitt RR, Reuter SR, et al: Expandable intraluminal graft: a preliminary study. Radiology 1985; 156:73-77.

3. Greenberg RK, Sternbergh WC 3rd, Makaroun M, Ohki T, Chuter T, Bharadwaj P, Saunders A; Fenestrated 
Investigators. Intermediate results of a United States multicenter trial of fenestrated endograft repair for juxtarenal abdominal aortic aneurysms. J Vasc Surg. 2009 Oct; 50(4):730-737.

4. Zarins CK; AneuRx Clinical Investigators. The US AneuRx clinical trial: 6-year clinical update 2002. J Vasc Surg 2003; 37:904-908.

5. Greenhalgh RM, Brown LC, Kwong GP. Comparison of endovascular aneurysm repair with open repair in patients with abdominal aortic aneurysm (EVAR trial 1), 30-day operative mortality results: randomized controlled trial. Lancet 2004; 364:843-848.

6. Blankensteijn JD, de Jong S, Prinssen M, van der Ham A. Two year outcomes afterconventional or endovascular repair of abdominal aortic aneurysms. N Engl J Med 2005; 352:2398-2405.

7. Lederle FA, Freischlag JA, Kyriakides TC, Padberg FT Jr, Matsumura JS, Kohler TR, Lin PH, Jean-Claude JM, Cikrit DF, Swanson KM, Peduzzi PN. Open Versus Endovascular Repair (OVER) Veterans Affairs Cooperative Study Group. Outcomes following endovascular vs. open repair of abdominal aortic aneurysm: a randomized trial. JAMA. 2009; 302(14):1535-42.

8. Walsh SR, Tang TY, Sadat U. Endovascular stenting versus open surgery for thoracic aortic disease: systematic review and meta-analysis of perioperative results. J Vasc Surg 2008; 47:1094-1098.

9. Makaroun MS, Dillavou ED, Wheatley $\mathrm{GH}$, Cambria RP. Five-year results of endovascular treatment with the Gore TAG device compared with open repair of thoracic aortic aneurysms. J Vasc Surg 2008; 47:912-918.

10. Verhoeven EL, Tielliu IF, Bos WT, Zeebregts CJ. Present and Future of Branched Stent Grafts in Thoracoabdominal Aortic Aneurysm Repair: A Single centre Experience. Eur J Vasc Endovasc Surg 2009; 38(2):155-161.

11. Drinkwater SL, Böckler D, Eckstein H.
The visceral hybrid repair of thoraco abdominal aortic aneurysms--a collaborative approach. Eur J Vasc Endovasc Surg 2009; 38(5):578-585.

12. Haulon S, D'Elia P, O'Brien N. Endovascular repair of thoracoabdominal aortic aneurysms. Eur J Vasc Endovasc Surg 2010; 39(2):171-178.

13. Greenberg RK, Sternbergh 3rd WC, Makaroun M. Intermediate results of a United States multicenter trial of fenestrated endograft repair for juxtarenal abdominal aortic aneurysms. Vasc Surg 2009; 50(4):730-737.

14. North American Symptomatic Carotid Endarterectomy Trial Collaborators. Beneficial effect of carotid endarterectomy in symptomatic patients with high-grade carotid stenosis.. N Engl J Med 1991; 325:445-453.

15. European Carotid Surgery Trialists' Collaborative Group. MRC European Carotid Surgery Trial: Interim results for symptomatic patients with severe (70$99 \%)$ or with mild (0-29\%) carotid stenosis. Lancet 1991; 337:1235-1243.

16. Executive Committee for the Asymptomatic Carotid Atherosclerosis Study. Endarterectomy for asymptomatic carotid artery stenosis. JAMA 1995; 273:1421-1428.

17. Randomised trial of endarterectomy for recently symptomatic carotid stenosis: final results of the MRC European Carotid Surgery Trial (ECST). Lancet 1998; 351:1379-1387.

18. Sidawy AN, Zwolak RM, White RA, Siami FS, Schermerhorn ML, Sicard GA. Outcomes Committee for the Society for Vascular Surgery. Risk-adjusted 30-day outcomes of carotid stenting and endarterectomy: results from the SVS Vascular Registry. J Vasc Surg 2009; 9(1):71- 9.

19. Silver FL, Mackey A, Clark WM, Brooks W, Timaran CH, Chiu D, Goldstein LB, Meschia JF, Fergus on RD, Moore WS, Howard G, Brott TG; CREST Investigators. Safety of stenting and endarterectomy by symptomatic status in 
the Carotid Revascularization Endarterectomy Versus Stenting Trial (CREST). Stroke 2011; 42(3):675-80.

20. Ederle J, Dobson J, Featherstone RL, Bonati LH, van der Worp HB, de Borst GJ, Lo TH, Gaines P, Dorman PJ, Macdonald S, Lyrer PA, Hendriks JM, McCollum C, Nederkoorn PJ, Brown MM. International Carotid Stenting Study investigators. Carotid artery stenting compared with endarterectomy in patients with symptomatic carotid stenosis (International Carotid Stenting Study): an interim analysis of a randomised controlled trial. Lancet 2010; 375(9719):985-97.

21. Hertzer NR, Bena JF, Karafa MT. A personal experience with direct reconstruction and extraanatomic bypass for aortobifemoral occlusive disease. J Vasc Surg 2007; 45:527.

22. Reed AB, Conte MS, Donaldson MC. The impact of patient age and aortic size on the results of aortobifemoral bypass grafting. J Vasc Surg 2003; 37:1219.

23. de Vries SO, Hunink MGM. Results of aortic bifurcation grafts for aortoiliac occlusive disease: a meta-analysis. J Vasc Surg 1997; 26:558.

24. Ricco J-B, Probst H. Long-term results of a multicenter randomized study on direct versus crossover bypass for unilateral iliac artery occlusive disease. J Vasc Surg 2008; 47:45-54.

25. Murphy TP. The role of stents in aortoiliac occlusive disease. New York, Thieme, 1998.

26. Uher P, Nyman U, Lindh M. Long-term results of stenting for chronic iliac artery occlusion. J Endovasc Ther 2002; 9:6775.

27. Carnevale FC, De Blas M, Merino S, et al: Percutaneous endovascular treatment of chronic iliac artery occlusion. Cardiovasc Intervent Radiol 2004; 27:447-452.

28. Adam DJ, Beard JD, Cleveland T, et al: Bypass versus angioplasty in severe ischaemia of the leg (BASIL): multicentre, randomised controlled trial. Lancet 2005; 366:1925-1934.

29. Vogel TR, Shindelman LE, Nackman GB, Graham AM. Efficacious use of nitinol stents in the femoral and popliteal arteries. J Vasc Surg 2003; 38:1178-1184.

30. Sabeti S, Schillinger M, Amighi J. Primary patency of femoropopliteal arteries treated with nitinol versus stainless steel self-expanding stents: propensity score-adjusted analysis. Radiology 2004; 232:516-521.

31. Ihnat DM, Duong ST, Taylor ZC, Leon LR, Mills JL Sr, Goshima KR, Echeverri JA, Arslan B. Contemporary outcomes after superficial femoral artery angioplasty and stenting: the influence of TASC classification and runoff score. $J$ Vasc Surg. 2008; 47(5):967-74.

32. Bosiers M, Hart JP, Deloose K. Endovascular therapy as the primary approach for limb salvage in patients with critical limb ischemia: experience with 443 infrapopliteal procedures. Vascular 2006; 14(2):63-69.

33. Wheatley K, Ives N, Gray R, Kalra PA, Moss JG, Baigent C, Carr S, Chalmers N, Eadington D, Hamilton G, Lipkin G, Nicholson A, Scoble J; ASTRAL Trial Investigators. Revascularization versus medical therapy for renal-artery stenosis. N Engl J Med 2009; 361(20):1953-62.

34. Murphy TP, Cooper CJ, Dworkin LD, Henrich WL, Rundback JH, Matsumoto AH, Jamerson KA, D'Agostino RB. The Cardiovascular Outcomes with Renal Atherosclerotic Lesions (CORAL) study: rationale and methods. $\mathrm{J}$ Vasc IntervRadiol. 2005; 16(10):1295-300.

35. Norgren L, Hiatt WR, Dormandy JA, Nehler MR, Harris KA, Fowkes FG; TASC II Working Group. Inter-Society Consensus for the Management of Peripheral Arterial Disease (TASC II). J Vasc Surg. 2007 Jan; 45 Suppl S:S5-67. 